\title{
Managing the COVID-19 Pandemic in China: Managing Trust and Accountability
}

\author{
Ronghui Yang, PhD candidate \\ Maastricht University \\ Care and Public Health Research Institute (CAPHRI) \\ Health, Ethics \& Society (HES) \\ r.yang@maastrichtuniversity.nl
}

In late 2019, China became the first country to be hit by the novel coronavirus pandemic, and many cities were locked down in 2020 to prevent transmission. The party chief in Wuhan, the hardest-hit Chinese city, announced that 'to contain the spread of virus and eliminate public panic, we must ensure that $100 \%$ of suspected patients and the close contact isolated, that $100 \%$ of febrile patients are treated and that all communities are implementing 24-hour closed management.' The country's response to the coronavirus has raised questions about control measures and establishing public accountability and trust in a non-democratic context. In my $\mathrm{PhD}$, I study how public health crises in China regarding food and vaccine scandals were portrayed as public problems and how they were discussed among Chinese stakeholders. Against this background, I trace discussions among citizens about the response to the coronavirus pandemic by following Chinese social media platforms, such as Zhihu, Weibo and WeChat. In these public arenas, three issues were fiercely discussed: the early warning system, regulation of governmental actors in Hubei Province and control over society.

A paper published by the Chinese CDC (Center for Disease Control and Prevention) in the NEJM revealed that the agency may have known about the human-to-human transmission of coronavirus half a month earlier than they informed the public, and this stimulated public distrust for the CDC's early warning system. A Zhihu user complained that the 'CDC cheated citizens'. With the escalation of coronavirus cases, reports about the poor organisation of Wuhan state for preventing contagion and the death of physician Li Wenliang, ignited widespread public anger towards Wuhan state. A resident commented on Weibo, 'the failed early warning on the coronavirus outbreak and the improper crisis response has widened the coronavirus outbreak. Leaders in the Chinese CDC and in the state of Wuhan should be punished strictly.'

In response, the central state immediately launched a series of measures to reinforce Wuhan state' response to the coronavirus and to reassure citizens. On January 24, it created an 'Internet + supervision' online system to collect evidence from society about the malpractice of local 
authorities, send inspection teams to investigate, and punish the local officials who failed to perform their duties. According to Wuhan News, 24 cadres in Hubei Province were punished for nonfeasance within a week. Encouraged by the central state, healthcare companies such as Dingxiang Doctor created information disclosure mobile applications for prompt coronavirus information updates. A Zhihu user wrote, 'these strategies largely stimulated Wuhan state's response to the virus and reassured citizens, but no national CDC officials have been punished for the failed activating of the early warning on the coronavirus.

China's anti-virus measures stressed the importance of controlling rumours. Media reports promoted information transparency but also fed rumours, such as that the virus was manufactured, which intensified social panic. To disprove such rumours, Tencent (sort of the Chinese Google) established 'the real-time rumour refutation of coronavirus online platform' to identify false reports. Local police tracked online rumours and detained the individual rumourmongers who disrupted public order. A friend suggested that controlling the disinformation spread by medical institutions for business interest is important as well. For instance, the Shanghai Institute of Materia Medica alleged that the Shuanghuanglian oral liquid could inhibit the virus, thus causing people to rush to buy it despite the lack of evidence supporting these claims. Meanwhile, individual trips were reined by states. In my hometown, which is near Wuhan, all the communities were closed, and residents had to stay home. People had to wear face masks on streets, and those who returned from travelling had their temperatures checked and were required to self-quarantine for 14 days. My parents said, 'staying at the flat for two months is boring, but we trust the states' strategies. Our life will return to normal soon as the coronavirus slows.'

These stringent anti-virus measures were effective, and the 'curve' has been flattened dramatically since mid-March 2020 in China. Through social media activity, the public compelled the central state to provide more information, develop an adequate crisis response and mitigate public anxiety. However, the Chinese political system lacks mechanisms that will allow citizens to hold state actors accountable for the overall crisis response and its effects. A Weibo user complained, 'we identified the strict control measures for managing the virus, but such excessive control has frustrated civil liberty. We had to submit ID numbers, health status and recent travelling history to companies and communities every day: we felt we were being monitored.' As such, there are many indications that the disproportionality of governmental intrusion and citizenship has worsened public dissatisfaction in China.

My research clarifies that child food and vaccination incidents in China evoked ambivalent responses from Chinese academia and other stakeholders. Some called for more state control, others for more participatory governance for public health (Yang et al, 2020). How the COVID-19 pandemic will affect ideas about accountability and trust in China remains to be studied. 


\section{References}

Yang, R., Penders, B., Horstman, K. (2020) Addressing Vaccine Hesitancy in China: A Scoping Review of Chinese Scholarship. Vaccines, 8 (1) 2 https://doi.org/10.3390/vaccines 8010002

\section{Keywords}

Governance; COVID-19; corona; coronavirus; pandemic; accountability; blame; responsibility; trust; public trust; credibility

Published in the Care and Public Health Research Institute Newsletter, Maastricht University (April 9, 2020). 